Article

\title{
Application of Game Theory to Conflict Management in a Construction Contract
}

\author{
Beata Grzyl, Magdalena Apollo *(i) and Adam Kristowski \\ Gdańsk University of Technology, Faculty of Civil and Environmental Engineering, 80-233 Gdańsk, Poland; \\ beata.grzyl@pg.edu.pl (B.G.); adam.kristowski@pg.edu.pl (A.K.) \\ * Correspondence: magdalena.apollo@pg.edu.pl; Tel.: +48-502-856-262
}

Received: 26 January 2019; Accepted: 31 March 2019; Published: 3 April 2019

check for updates

\begin{abstract}
Interest has recently grown in the application of game theory (GT) to solve a number of diverse problems in the field of construction. The use of GT by a general contractor (GC) of construction works to indicate the best strategy leading to winning court proceedings in a situation of conflict with investor (IN), has not been investigated until now. Thus the aim of this paper is to indicate the optimal strategy from the GC viewpoint in a conflict situation with the IN. The article presents a list of the most common causes of conflict between parties of a construction work contract, defines the background of the problem and the cause of the dispute, and subsequently the authors generate a theoretical model of the game. Based on the analyzed game model, the expected payoffs for players were calculated and the probability boundary value determined in making the GC apply the indicated strategy. The study results show that while the probability of issuing a judgment favorable for the GC is at least equal to 0.69 it is justified to use an aggressive strategy. The analysis also confirms that from the financial perspective, litigation in most cases of conflicts in the area of construction should be the ultimate choice.
\end{abstract}

Keywords: civil engineering; construction contract; court strategy; conflict modeling; decision analysis; game theory

\section{Introduction}

In recent decades, there has been a lot of interest in the applications of game theory (GT) in science. In construction practice, games find application in modeling in the following situations:

- tender preparation, selection of a contractor for construction works [1-4],

- entities cooperation [5],

- setting a portfolio of orders,

- building a market entry strategy for a new entity, product or service (technology),

- negotiating terms and conditions of cooperation of the parties to the contract [6,7],

- mediation between contractors,

- wage negotiations with employees,

- $\quad$ selection of the optimal technological variant [8,9],

- simulation of the course of conflict between entities competing in the same market, exploiting the same resource (e.g., employees, materials) [10-15],

- $\quad$ simulating the course of the "price war" between sellers of construction production, enforcing obligations of the parties to the contract [16],

- simulating the course of the conflict resolved in court,

- $\quad$ simulating the operation of the entity (development company, executive, warehouse of building materials) in a situation of high competition in the construction market [17-19], 
- determining the level, scope, and type of construction production affected by the market situation [20],

- identification, analysis and modeling of investment risk [21-24],

- management in the investment process [8,25-29],

- optimization of investment projects [30-33].

Numerous reasons for conflicts between entities involved in the construction process can be identified [34-39] and categorized by the stage of occurrence, as follows:

1. During the preparation and submission of tender offers, the contractors are obliged to verify the project documentation or the functional and operational program (FOP), to identify their defects, to examine the area of planned construction in regard to provision of utilities and to geological and geotechnical conditions.

2. During project execution, after the contract is signed, the selected contractor is obliged to remove the identified defects of the project documentation or the FOP and to complete additional works.

3. During the final inspection the following causes of conflict can be identified: making the acceptance of works by the investor affected by the circumstances beyond the contractor's control or unrelated to the construction process (e.g., delivery and launch of the production line by another supplier, service provider).

The literature review supplementing the paper indicates that GT is widely used in solving many diverse problems in the field of construction. In the authors' opinion, the use of game theory by the general contractor (GC) of construction works to indicate the best strategy leading to winning court proceedings in a situation of conflict with the investor (IN), has not yet been the subject of research. Therefore, this approach to the problem is a novelty in the field of construction. The article presents a list of the most common causes of conflicts between parties of the construction work contract, defines the background of the problem, and the cause of the dispute, on this basis, the authors generate a theoretical model of the game.

Interdisciplinary and behavioral factors act strongly on the decision-making processes occurring at the level of individuals but also of economic organizations. A full understanding of economic decisions of parties to a contract for construction works requires a thorough and comprehensive analysis of many factors of an economic, social, and psychological nature, etc. The situation presented in this article is very difficult to describe (also in the field of behavioral psychology of parties involved-players), therefore the authors have made specific assumptions. Among others that both players make decisions and take actions rationally i.e., they select the best decision for themselves (from the point of view of results), their goal is therefore to obtain the maximum payoff (profit) and/or to minimize losses. In practice, "rational choice" depends on many internal and external factors. For this reason it is difficult to define the assumptions of the game and determine the consequences of actions taken by the players. This is caused by the fact that the decision-makers of a fundamental influence on the course of an investment project are in many cases guided by individual premises and a way of thinking that is different from the "average". In practice, obvious "responses" of the player to a specific move made by the opponent, in some cases do not apply. Often the decisions are influenced by the mutual relations of contractors, their style of work, character traits, e.g., risk taking or aversion, willingness to prove their case at all costs, offended ambition, etc. It is obvious that issues related to psychology, behavior, habits, and motives are of great importance and a subject of numerous scientific works conducted around the world, e.g., refs. [40-43].

\section{Introductory Example}

Consider the following conflict game. In this game Player 1 can be in two states: Strong and Weak. Payoffs for both players differ in each of the cases (see Table 1). 
Table 1. Utilities—introductory example.

\begin{tabular}{cccc}
\hline \multirow{3}{*}{ Player 1 } & Strong & Fight & Not \\
& Fight & $1,-2$ & $2,-1$ \\
& Not & $-1,2$ & 0,0 \\
\hline \multirow{3}{*}{ Player 2 } & Weak & Fight & Not \\
& Fight & $-2,1$ & $2,-1$ \\
& Not & $-1,2$ & 0,0 \\
\hline
\end{tabular}

Suppose both Players fight then the outcome depends whether Player 1 is "Strong" or "Weak". Consequently the Nash Equilibrium will also differ. Suppose both Players know whether Player 1 is going to be strong or weak. If Player 1 is strong then he has a dominant strategy of fighting. Thus Player 2 will not fight-Nash Equilibrium is \{Fight, Not\}. If Player 1 is weak then the Nash equilibrium is \{Not, Fight\}. Suppose Player 2 does not know what Player 1 is going to be. So he assigns a probability " $\mathrm{p}$ " Player 1 is strong and probability " $1-\mathrm{p}$ " Player 1 is weak. Player 2 expected payoffs when he fights: $p(-2)+(1-p)(1)$, expected payoff when not fighting: $(-1)$. Therefore, Player 2 should fight if $\mathrm{p}(-2)+(1-\mathrm{p})(1)>-1$, i.e., if $\mathrm{p}<2 / 3$.

In the case of incomplete information Player 2 to make the best decision (fight or not) would have to collect relevant evidence that would enable him to estimate the probability of Player 1's state [44].

Such situations are quite common when considering conflict problems that arise in the construction industry. Each competitor's decision depends on the expected actions of the other players of the game. The problem of interactive decision-making is solved well by the tools of game theory.

The effective management of a building engineering project is a key issue towards its final success. The management entirety covers all activities aimed at assuring basic project features related to time, cost, and quality. It also addresses disturbance reduction and solution of the conflicts between the project parties in its course.

The situation outlined by this paper triggers a dedicated game model to reflect the conflict, analysis of available information which was provided on the basis of GT methodology. The model structure covers the processes making up the conflict environment and the basic information acting upon the final results. GT was used as a tool to support the decision-making and management of risk triggered by imprecise and disadvantageous statements of the building engineering operational agreement. The conflict was modeled and the income of the parties was simulated on the basis of an economic calculation. The article points out the possibility of incorporating the proposed model and the GT application to assess the project risk, possible financial effects, and the outcomes of decisions made by the agreement parties. The proposed solution joins the fields of building economics, risk analysis, and sustainable development of the building engineering world. Such a complex approach to the management of a building investment project is bound to substantially raise its success perspectives, subsequently increasing the sustainable development in the field of the building industry and the economy.

\section{The Cause of Conflict between the GC and the IN-Description and Structure of the Research Problem}

Due to serious defects of the project documentation supplied by the IN, identified during works execution, the additional scope of works was introduced. The GC contacted the IN to sign an annex to the contract, increasing the agreed lump-sum remuneration and extending the deadline for the investment. The IN rejected the claims of the GC. Considering the consequences of the available strategies at the stage of work execution, the GC decided to continue works. All works were completed in accordance with the contract, as well as the additional works, resulting in an increase of cost and an extension of the deadline in relation to the provisions of the contract. After investment completion the IN applied contractual penalties for failing to meet the deadline and deduced this amount from the performance guarantee bond. The GC referred the case to court demanding the return of contractual 
penalties withheld by the IN, the cost of additional works and compensation for lost profits. Both sides need to select a strategy for litigation and identify its consequences.

To represent the game between the GC and the IN the following assumptions are made:

- value of the signed contract for construction works: 55 million,

- total time of investment completion: 500 workdays,

- value of the additional works completed by the GC: 1.5 million,

- amount of contractual penalties for failing to meet the deadline: 2.0 million,

- cost of profits lost: 2.0 million.

The case study of the game between the GC and the IN presented in this article refers to a real situation. However, due to the lack of consent of the GC to use the names of entities involved in the court proceedings, the article does not state the names of the two large companies operating in Europe or the name of the completed investment. The costs of conducting a court trial (Table 2) and the payoff amount for both game states (Tables 3 and 4) refer to the same real situation and were established based on information provided by experts (i.e., the GC employees and lawyers involved in the lawsuit).

\section{Game Model Proposition}

The game has two conflicted players- the GC and the IN. It is analyzed from the GC's perspective and aims to identify the best strategy for winning the litigation and maximizing the payoff. The analysis applies GT methodology. It is a game with imperfect information and two players.

\subsection{Assumptions for the Constructed Game Model}

The selection of the strategy to be applied depends on the payoff and the player's expectations regarding the opponent's actions. The same decision space is assumed for both players. The two most probable strategies available to players are: aggressive or conciliatory.

1. The aggressive strategy means taking a decisive action and actively searching for the opponent's weaknesses. Its disadvantage is the considerable resources needed to prove the case in court (evidence e.g., numerous witnesses, expert opinions). It is assumed that the cost of long-term litigation is 2.6 million.

2. The conciliatory strategy means demonstrating readiness for dialogue and searching for rational compromise. The conciliatory strategy of the winning side results in smaller benefits than the aggressive one. Its advantage is significantly shorter litigation. It is assumed that the total cost of litigation is 0.5 million.

3. In the case of taking asymmetric actions (one of the players applies aggressive strategy, the other conciliatory) the cost of litigation varies for both sides. It is assumed that for the aggressive player it will be 2.0 million, and for the conciliatory 1.0 million.

The decision space available results in four possible strategic combinations: two aggressive players (long and costly litigation), the conciliatory approach of both players (quick conflict resolution), two situations in which one of the sides assumes an aggressive approach and the other is willing to compromise.

A non-cooperative game can be written as the pair $G(M, S, \Omega, J)$. where:

$S$ - the strategy space,

$\Omega$-the action space,

$J$-the vector of objective functions associated to players,

$M$-the set of players. 


\section{A Formal Description of the Game}

A conflict between the GC and the IN occurs here. The conflict is resolved by the court. There are specific withdrawals amounts, depending on the decision made by the court. Each party may apply a specific strategy (aggressive or conciliatory). There are therefore specific combinations of strategies adopted by players and two states of the game. In order to win the lawsuit, the GC considers an aggressive strategy in court. The amount requested by the GC is known to both parties. However, there is an additional cost " $\mathrm{C}$ " associated with the preparation for the process, known only to the GC. The IN has no knowledge of whether the cost of preparing the GC for the process is $C=0$ or $C=x$. The GC wants to win the trial, but must decide whether to adopt an aggressive strategy (and pay the cost of preparing for the process 2.6 million) or conciliation (and incur a cost of 0.5 million). The IN does not have full knowledge about " $\mathrm{C}$ " i.e., does not know the choice of strategy, the GC must decide which strategy to use in court. As a result, we have two payout matrices. The first is for the GC to adopt an aggressive strategy and incur a high cost, the other for a conciliation strategy and a lower cost. The best strategy for the GC can be indicated based on the payout table for two game states. It is assumed that the GC is making the first move. The game should be considered a game of imperfect information-players are not aware of the action taken by other players and the costs associated with it.

A problem arises if the opponent's probability of choosing a strategy cannot be estimated. If there is a problem of dependence, i.e., the GC must guess the IN strategy to choose its optimal version, it is possible to enter the nature node, which in our case determines the win/loss of the GC in the court. Figure 1 shows the transformation from incomplete to imperfect game. The left branch is about the situation-the GC wins in court, the right loses. The information provided in the bottom of the tree is linked to payouts (Tables 2 and 3). The node nature performs the first move and randomly selects the case- the GC is aggressive with the probability $\mathrm{p}$, complementary to the probability $(1-\mathrm{p})$.

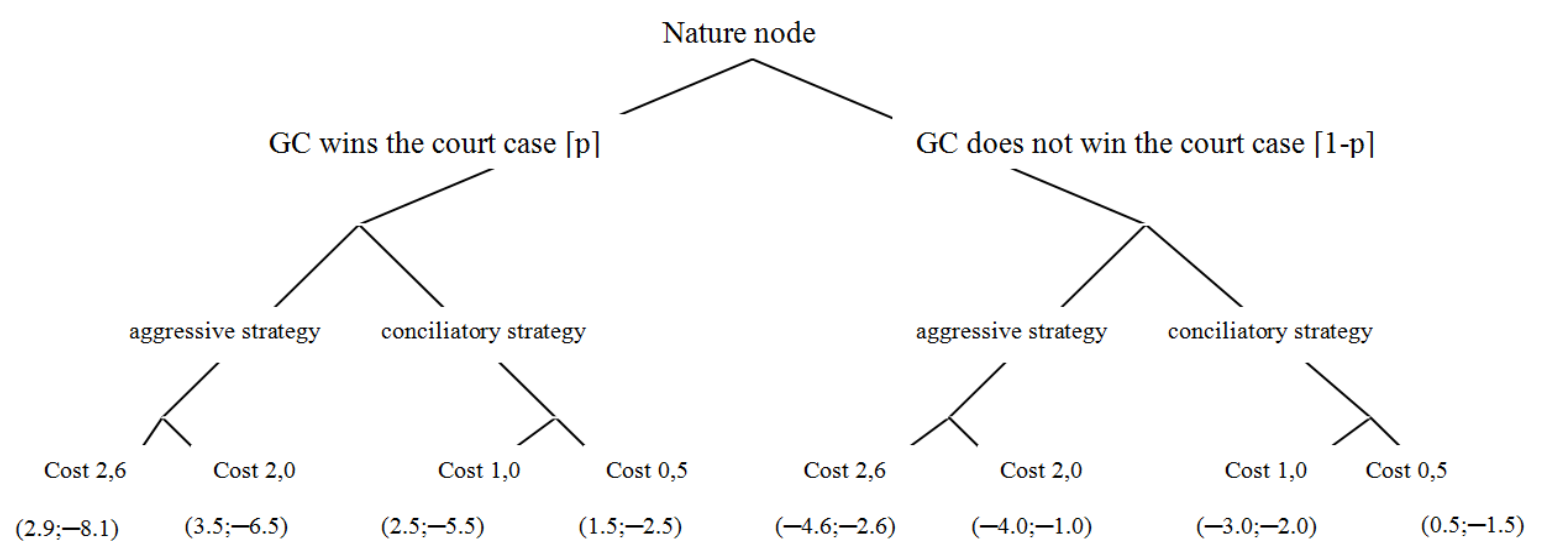

Figure 1. Imperfect game-the sequence of events.

The game is analyzed from the GC viewpoint, who brought the case to court. The first move is carried out by the GC as an entity that wants to recover additional incurred and unplanned expenses in court. Before the trial begins, the GC analyzes various scenarios that may occur. Regarding all the possibilities the GC wants to choose the best solution i.e., the one with the largest possible payoff, which depends, among others, on the strategy adopted by both parties.

The GC does not know which strategy the IN will select, therefore both outcomes (the case in court will be won by the GC, or by the IN) and four strategy combinations are considered. In order to choose the optimal strategy for conducting a "game" in court, the GC must effectively predict the IN's actions. At the same time, the GC knows that an aggressive strategy will be beneficial, only while favorable circumstances occur in the "game". It is assumed that if the GC collects "strong evidence" (including irrefutable and convincing opinions of witnesses and experts), he will choose an aggressive strategy, which will probably result in the IN applying the conciliatory strategy. 
The game setup, the sequence of events, and the points in the game, where decisions are made by both parties are specified in Figure 1.

According to the assumption that the parties must commit to any action (aggressive, conciliatory) before the court trial, the nature (pseudo player) moves first, determining the favorability of the circumstances for the GC to win. This probability is called the 'border' value, due to the GC fully undertaking an aggressive strategy. The GC does not know this value before choosing the aggressive strategy.

The game model includes two basic stages.

Stage 1-Development of the model, including:

- data acquisition,

- analysis and description of the conflict origin,

- establishing assumptions for the game model,

- determining the preliminary rules and the game conditions,

- determining the strategies that can be applied by each player, game states and payoff amounts,

- calculation of the payoff amount for the two game states (court case won/lost by the GC); the same probability distribution of the court decision being favorable/unfavorable for the GC is assumed ( $50 \%$-the GC won, $50 \%$-the IN lost, 50\%—the IN won, 50\%—the GC lost), not considering specific circumstances and evidence affecting the court decision.

- $\quad$ estimating the minimum probability of favorable circumstances at which it is beneficial to apply a specific strategy.

Stage 2-Simulation of probability variation of new circumstances affecting the course of a court hearing-game management (variable modeling), includes:

- collecting and interpreting new information,

- entering new information,

- probability distinction of a court judgment favorable for the GC-probability analysis in the range from 0.0 (the GC loses the court case) to 1.0 (the GC wins the court case), considering new circumstances and evidence favorable for the GC,

- determining the scope of changes in the expected payoffs for both players depending on the variable probability value of a given game state (calculation of the payoff values for different cases),

- analysis and interpretation of the results obtained in the aspect of taking a rational decision by the GC.

\subsection{Game States}

In order to define the payoffs for both players [3], the court ruling must be considered. The game is defined for two equally probable and separate states: 1 . The GC will certainly win, 2. the court will certainly rule in favor of the IN.

The Nash equilibrium, found in Tables 3 and 4 is under the strict assumption that both players know with 'certainty' who wins the case. A strictly dominant strategy of the IN is to choose conciliatory', regardless of who wins. That is because the IN provides a strictly dominant strategy to be conciliatory in order to focus on the choices of the GC for the remainder of the solutions.

Due to game states 1 and 2 the payoff tables have been defined. The uncertainty of each game state is taken into account assuming the probability of a given state (due to game state 1 the probability equals 1.0, due to game state 2 it is: 0.0). At the current conflict stage the court ruling is unknown, therefore the next part of the paper considers two game states and assumes the same probability distribution of winning/losing the litigation by any side (Tables 2-4). Due to game states 1 and 2, it is also assumed that the attitude of both players to the court 'game' is the same. 
The analysis focuses on the two most probable game states and the two most probable strategies (aggressive or conciliatory conflict resolution) that players may start. An identical decision space due to both players and the specific model assumptions both hold. Two selected-main game states (the GC won/lost) - are not the only possible payoff scenarios for the players. In practice, it is possible that the GC wins the case and receives a lower value of the claim. In order to show the gameplay and possible payoffs, the authors referred to examples-the arbitrarily selected solutions from a wide range of other possibilities and intermediate cases. The decision space is complex, thus the issue is the subject of further research currently carried out by the authors.

\subsection{Payoff Tables for Two Game States}

The calculation considers financial profits and losses dependent on the court ruling, the strategy applied by the player and the cost of litigation. Those elements are considered for each of four possible combinations of strategies and two game states. It is assumed that the costs related to applying each strategy do not vary depending on the game state. The information presented in payoff tables (Tables 2-4) are expressed in millions of monetary units.

Table 2. Litigation cost in millions considering each combination of strategies applied by players.

\begin{tabular}{c|cc}
\hline $\begin{array}{c}\text { Player 1-Investor (IN) } \rightarrow \\
\text { Player 2-General Conractor (GC) } \downarrow\end{array}$ & Aggressive Strategy & Conciliatory Strategy \\
\hline Aggressive Strategy & $(-2.6 ;-2.6)$ & $(-2.0 ;-1.0)$ \\
Conciliatory Strategy & $(-1.0 ;-2.0)$ & $(-0.5 ;-0.5)$ \\
\hline
\end{tabular}

\subsubsection{Game State 1}

If the GC applies an aggressive strategy and wins, the payoff will be 5.5 million (2.0 million-contractual penalties deducted by the IN; 1.5 million-the cost of additional works; 2.0 million-compensation for lost profits). The IN will lose such an amount (loss -5.5 million).

If the GC applies conciliatory strategy and wins, the payoff will be 3.5 million (2.0 million-contractual penalties deducted by the IN; 1.5 million-the cost of additional works). The IN will lose this amount (loss -3.5 million) - see Table 3 for details (the calculations include the cost of litigation dependent on the selected strategy according to Table 2).

Table 3. Payoff table in millions of monetary units, if the GC wins the court case.

\begin{tabular}{c|cc}
\hline $\begin{array}{c}\text { Player 1-Investor (IN) } \rightarrow \\
\text { Player 2-General Contractor (GC) } \downarrow\end{array}$ & Aggressive Strategy & Conciliatory Strategy \\
\hline \multirow{2}{*}{ Aggressive Strategy } & $5.5-2.6=2.9-5.5-2.6=-8.1$ & $5.5-2.0=3.5$ \\
& $(2.9 ;-8.1)$ & $(3.5 ;-6.5)$ \\
\hline Conciliatory Strategy & $3.5-1.0=2.5-3.5-2.0=-5.5$ & $2.0-0.5=1.5-6.5$ \\
$(2.5 ;-5.5)$ & $(1.5 ;-2.5)$ \\
\hline
\end{tabular}

It is assumed that in the event of both sides applying the conciliatory strategy and the GC winning, to resolve the conflict quickly, the GC will agree to the reimbursement of only 2.0 million (contractual penalties). As a result, the IN will lose this amount (loss -2.0 million). Nash equilibrium [4] exists for the case when the GC applies aggressive strategy and the IN conciliatory strategy to resolve the conflict. In such an event, the GC's payoff will be 3.5 million (profit), the IN's a 6.5 million (loss).

\subsubsection{Game State 2}

If the IN wins, the GC will not get a refund of contractual penalties, incurring a loss ( -2.0 million). The IN will not gain 2.0 million, because earlier this amount was deducted from the GC's performance bond (see Table 4, this amount is not considered on the IN's side). From the IN's perspective, the game focuses on minimizing losses not maximizing profits. 
In a conciliatory scenario, it is assumed that the IN and the GC agree to split the amount of 2.0 million (contractual penalties) evenly. The GC receives 1.0 million and the IN loses the same amount. Once again, the calculations include the cost of litigation dependent on the selected strategy according to Table 2.

Table 4. Payoff table in millions of monetary units, if the IN wins the court case.

\begin{tabular}{c|cc}
\hline $\begin{array}{c}\text { Player 1-Investor (IN) } \rightarrow \\
\text { Player 2-General Contractor (GC) } \downarrow\end{array}$ & Aggressive Strategy & Conciliatory Strategy \\
\hline Aggressive Strategy & $-2.0-2.6=-4.6 \quad 0-2.6=-2.6$ & $-2.0-2.0=-4.0 \quad 0-1.0=-1.0$ \\
& $(-4.6 ;-2.6)$ & $(-4.0 ;-1.0)$ \\
\hline Conciliatory Strategy & $-2.0-1.0=-3.0 \quad 0-2.0=-2.0$ & $1-0.5=0.5(0.5 ;-1.5)$ \\
\hline
\end{tabular}

Nash equilibrium [45] exists if the GC and the IN apply conciliatory conflict resolution strategy. In such an event the GC's payoff will be 0.5 million (profit), the IN a 1.5 million (loss).

\subsection{Payoff Analysis for Two Game States}

Table 3 presents the game solution for game state 1, i.e., the GC winning. It indicates that the best combination of strategies for the GC (Nash equilibrium) is if the GC applies an aggressive strategy and the IN a conciliatory strategy. In such event, the GC's payoff will be 3.5 million (profit), the IN's a 6.5 million (loss). The result of the game indicates the dominant strategies for players.

Table 4 presents the game solution for game state 2, i.e., the IN winning. The same payoff values for both players were applied, as for the game state 1 . In this case, the players' payoff amounts are different from game state 1 . The best strategy for the GC is also different.

In both game states players analyze the application of symmetric (aggressive-aggressive, conciliatory-conciliatory) and asymmetric actions (aggressive-conciliatory, conciliatory-aggressive) strategies. From the IN's perspective, due to both game states, applying the conciliatory strategy is more beneficial if the IN loses. It should be emphasized that in no combination of the game states and strategies, does the IN achieve positive payoffs. In game state 2 (the IN wins), the GC's payoff is positive ( 0.5 million) only in one case, the IN's loss is then -1.5 million.

The game state has a significant impact on the players' payoffs. If the probability of the GC winning the case is high then the best strategy for the GC will be aggressive. However, if the ruling is in favor of the IN, only with conciliatory strategy the GC has a chance for the positive payoff (profit 0.5 million), otherwise, he will incur losses (negative payoff).

The situation presented in this article is very difficult to describe (also in the field of behavioral psychology of parties involved-players), and the rational choice depends on many internal and external factors. In order to simplify the problem it was assumed that both players make decisions and take actions rationally i.e., they select the best decision for themselves (from the point of view of results), their goal is therefore to obtain the maximum payoff (profit) and/or to minimize losses.

The issue of interaction of strategic players (GC, IN) in a behavioral aspect, i.e., "rational choice" and "rational behavior" in the described conflict situation, is the subject of further research conducted by the authors.

\subsection{Expected Payoffs for Players for the New Probability Distribution}

Based on the analysis of the existing rulings, for similar cases, it was determined that they are not consistent and depend on the features of individual cases. Referring to the real conditions, the following probability distribution of two game states was arbitrarily adopted: $50 \%$-ruling in the GC's favor, $50 \%$-in the IN's. In this case, the payoffs are 2.0 million for the GC (profit), -4.0 million for the IN (loss). 


\subsection{Border Value of Probability, Model Analysis, Simulations}

In order to select the right strategy for the GC, the important information is the minimal (border) probability of favorable circumstances, at which an aggressive strategy (in game state 1) is beneficial. The probability border value can be calculated for each player. Due to the GC it is calculated from formula (1) $[3,4]$.

$$
p_{1}^{*} \cdot u_{G C 11}+\left(1-p_{1}^{*}\right) \cdot u_{G C 12} \geq p_{1}^{*} \cdot u_{G C 21}+\left(1-p_{1}^{*}\right) \cdot u_{G C 22}
$$

where:

$p_{1}^{*}$ - probability border value is understood as the minimal probability of circumstances favorable for the contractor, in which it pays off to apply the aggressive strategy.

$u_{G C 11}$ - the payoff for the GC when the aggressive strategy is used for game state 1 ,

$u_{G C 12}$ - the payoff for the GC when the aggressive strategy is used for game state 2,

$u_{G C 21}$ - the payoff for the GC when the conciliatory strategy is used for game state 1 ,

$u_{G C 22}$ - the payoff for the GC when the conciliatory strategy is used for game state 2 .

Figure 2 shows the relation between expected payoffs for players (GC, IN) in millions of monetary units. It can be observed, that to effectively apply the aggressive strategy in court, the GC must, with at least 0.69 probability (Figure 2), know that favorable circumstances will occur (numerous witnesses, hard evidence, expert opinions, a passive and poorly prepared court case for the IN) and have a decisive influence on the court's ruling. It can be also seen from the Figure 2, that the expected payoffs of both players depend on the changing probability value (from 1.0 to 0.0 ) of winning the court case by the GC.

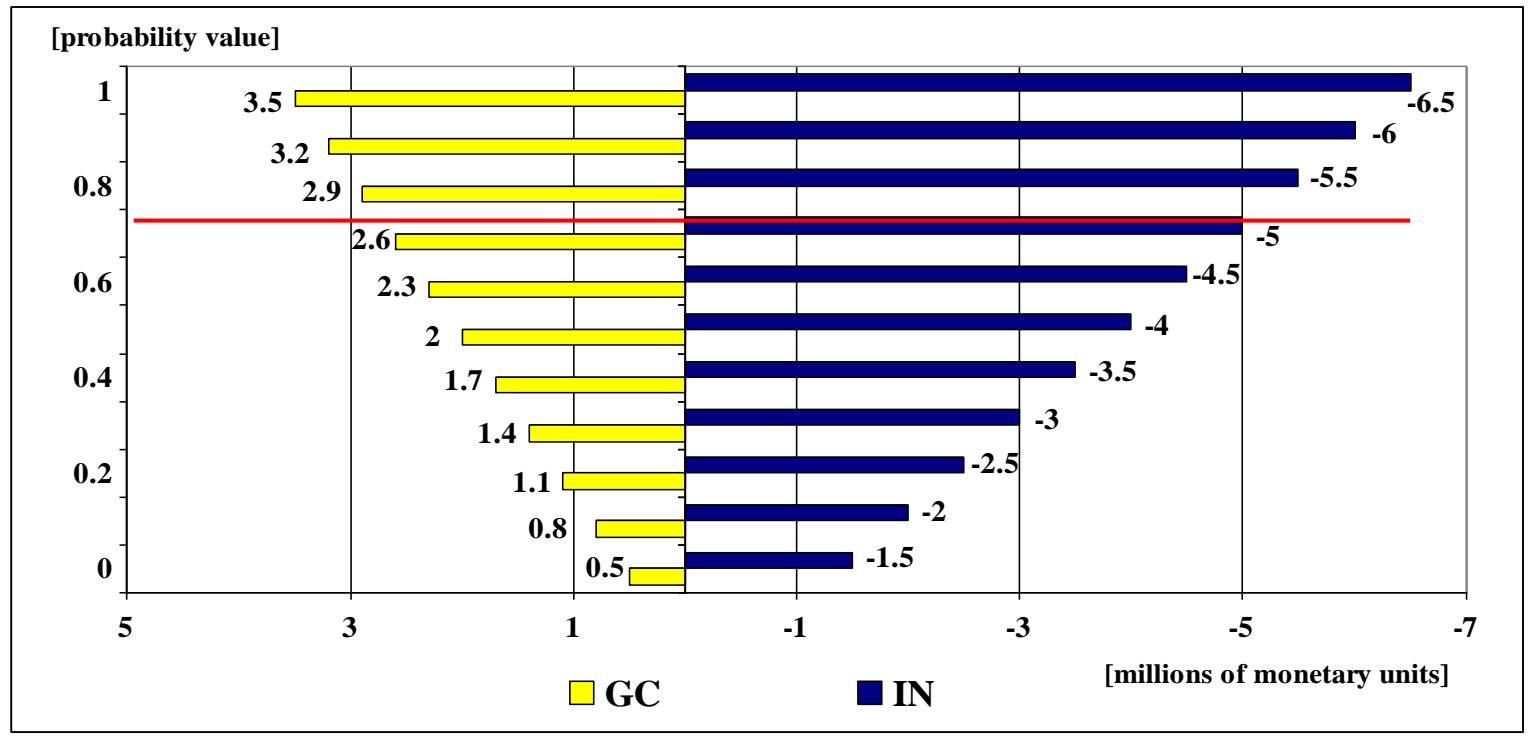

Figure 2. Simulation showing relation between expected payoffs for players (General Contractor-GC, Investor-IN) in millions of monetary units.

The extreme payoff values refer to game states 1 and 2, respectively. It is assumed that the strategies and decision spaces available remain unchanged, i.e., players still have the same optimal strategies in each game state. By changing the probability distribution of the GC winning, the expected payoffs change. The simulation shows that as the likelihood of the GC winning increases, the expected GC's payoff increases and the IN's decreases (the loss increases). Figure 2 shows the expected payoffs for players depending on the probability value of the judgment in favor of the GC. 


\section{Conclusions and Recommendations}

In this paper the optimal strategy for the GC in a situation of conflict with the IN was analyzed. Based on the analysis of the game model, expected payoffs for players were calculated and the probability border value, at which the GC should apply the indicated strategy, determined.

The calculated values of expected payoffs indicate the benefits of applying the available strategies by both players. Selecting the optimal strategy for the GC depends on the predicted approach of the court. Due to the GC in the first state of the game, the aggressive strategy is dominant, in the second state, the conciliatory. The conducted analysis also showed that the main goal of the IN, in each combination of strategy and the two states of the game, is to limit the losses, not to gain a profit. For the IN in both states of the game, the conciliatory strategy is dominant.

It should be emphasized that the two options selected in the article (i.e the main game states win/loss of the GC) are not the only payoff options for players. In practice, the GC may, for example, win a case with a small compensation, and be awarded a lower or total value of the claim. There is therefore a wide spectrum of decisions to consider, and the decision space is very complex. This issue is the subject of further research currently being carried out by the authors.

The article presents preliminary results of research, aiming to determine whether it is possible and justified to apply game theory to solve conflict situations arising in the field of construction. So far, the authors have analyzed one single selected example. The further research is aimed at the possibilities of using the GT to solve additionally selected problems. Only then will it be possible to calibrate the proposed model and formulate broader recommendations for managers and consultants in the construction industry.

The analysis also confirmed that due to financial perspective, litigation in most conflict cases in the construction field should be the last choice. Other less expensive ways of resolving a conflict are such as an expert settling a dispute, an arbitration committee, or mediation.

Thus it should be emphasized that GT is a valuable tool supporting the decision process to take an advantage over an opponent, while the assumptions are correct, reflecting the situation features. An important advantage of conflict modeling is the fact that decisions are based on rational premises and calculations.

It is assumed that it is possible to practically implement the proposed method to model the results on the stage of analysis of potential decisive scenarios by the parties e.g., prior to settling the issue in court. A single simulation of a given conflict (scenario modeling) due to given project parameters, next gains and losses may be analyzed due to undertaking the selected operations, subsequently, effective decision making. The article points out a novel approach to investment project management, to practically raise the efficiency of the operations undertaken by the parties of a building operations agreement, due to limiting (or rejecting) redundant actions and the parties' funds, to finally bring about sustainable development of the engineering field.

Author Contributions: Conceptualization, B.G. and A.K.; methodology, B.G.; validation, A.K. and M.A.; formal analysis, M.A.; investigation, B.G.; resources, B.G.; data curation, B.G.; writing—original draft preparation, B.G.; writing-review and editing, M.A.; visualization, M.A.; supervision, A.K.; project administration, M.A.

Conflicts of Interest: The authors declare no conflict of interest.

\section{References}

1. Zavadskas, E.K.; Turskis, Z.; Tamošaitienè, J. Contractor selection of construction in a competitive environment. J. Bus. Econ. Manag. 2008, 9, 181-187. [CrossRef]

2. Tamošaitiene, J.; Turskis, Z.; Zavadskas, E.K. Modeling of Contractor Selection Taking into Account Different Risk Level. In Proceedings of the 25th ISARC, Vilnius, Lituania, 26-29 June 2008; pp. 676-681. [CrossRef]

3. Osborne, M.J. An Introduction to Game Theory, 1st ed.; Oxford University Press: New York, NY, USA, 2003; ISBN 978-0-19-512895-6. 
4. $\quad$ Osborne, M.J.; Rubinstein, A. A Course in Game Theory, 1st ed.; The MIT Press: Cambridge, MA, USA, 1994; ISBN 978-0-262-65040-3.

5. Halac, M. Relationship Building: Conflict and Project Choice over Time. J. Law Econ. Organ. 2014, 30, 683-708. [CrossRef]

6. Yang, Y.; Wang, M. Analysis on the interests of construction parties in project management model based on the game theory. In Proceedings of the 2009 Chinese Control and Decision Conference, Shanghai, China, 16-18 December 2009; pp. 4512-4516. [CrossRef]

7. Anderson, L.L., Jr.; Polkinghorn, B. Managing conflict in construction megaprojects: Leadership and third-party principles. Confl. Resolut. Q. 2008, 26, 167-198. [CrossRef]

8. Zavadskas, E.K. Game Theory in Building Technology and Management; Vilnius: Technika, Lithuanian, 2004.

9. Ibadov, N. Determination of the Risk Factors Impact on the Construction Projects Implementation Using Fuzzy Sets Theory. Acta Phys. Pol. A 2016, 130, 107-111. [CrossRef]

10. Barough, A.S.; Shoubi, M.V.; Skardi, M.J.E. Application of Game Theory Approach in Solving the Construction Project Conflicts. Procedia Soc. Behav. Sci. 2012, 58, 1586-1593. [CrossRef]

11. Wu, G.; Wang, H.; Chang, R. A Decision Model Assessing the Owner and Contractor's Conflict Behaviors in Construction Projects. Available online: https:/ /www.hindawi.com/journals/ace/2018/1347914/ (accessed on 2 November 2018).

12. Wu, G.; Liu, C.; Zhao, X.; Zuo, J. Investigating the relationship between communication-conflict interaction and project success among construction project teams. Int. J. Proj. Manag. 2017, 35, 1466-1482. [CrossRef]

13. Puck, J.; Pregernig, U. The effect of task conflict and cooperation on performance of teams: Are the results similar for different task types? Eur. Manag. J. 2014, 32, 870-878. [CrossRef]

14. Mateo, S.C.; Ramón, J. The use of Game Theory to solve conflicts in the project management and construction industry. Int. J. Inf. Syst. Proj. 2015, 3, 43-58. [CrossRef]

15. Yiu, T.W.; Cheung, S.O. Behavioral Transition: A Framework for the Construction Conflict-Tension Relationship. IEEE Trans. Eng. Manag. 2007, 54, 498-505. [CrossRef]

16. Yuan, H.; Ma, H. Game Analysis in the Construction Claim Negotiations. Procedia Eng. 2012, 28 , 586-593. [CrossRef]

17. Sacks, R.; Harel, M. An economic game theory model of subcontractor resource allocation behavior. Constr. Manag. Econ. 2006, 24, 869-881. [CrossRef]

18. Motchenkova, E. Determination of optimal penalties for antitrust violations in a dynamic setting. Eur. J. Oper. Res. 2008, 189, 269-291. [CrossRef]

19. Brockman, J.L. Interpersonal Conflict in Construction: Cost, Cause, and Consequence. J. Constr. Eng. Manag. 2014, 140, 4013050. [CrossRef]

20. Zavadskas, E.K.; Peldschus, F. Application of Games Theory in Preparation for Building Production; Vilnius Engineering Civil Institute: Vilnius, Lithuania, 1986.

21. Hwang, B.-G.; Zhao, X.; Yu, G.S. Risk identification and allocation in underground rail construction joint ventures: contractors' perspective. J. Civ. Eng. Manag. 2016, 22, 758-767. [CrossRef]

22. Reneke, J.A. A game theory formulation of decision making under conditions of uncertainty and risk. Nonlinear Anal. Theory Methods Appl. 2009, 71, e1239-e1246. [CrossRef]

23. Tomczak, M.; Jaśkowski, P. Application of type-2 interval fuzzy sets to contractor qualification process. KSCE J. Civ. Eng. 2018, 22, 2702-2713. [CrossRef]

24. Apollo, M.; Kembłowski, M.W. Modelowanie ryzyka inwestycyjnego przy użyciu OOBN. Mater. Bud. 2016, 48-49. [CrossRef]

25. Kapliński, O; Tamošaitiene, J. Game theory applications in construction engineering and management. Ukio Technologinis ir Ekonominis Vystymas 2010, 16, 348-363. [CrossRef]

26. Peldschus, F.; Zavadskas, E.K.; Turskis, Z.; Tamosaitiene, J. Sustainable assessment of construction site by applying game theory. Inzinerine Ekon. Eng. Econ. 2010, 3, 223-236.

27. Peldschus, F. Multi-attribute decisions in construction. Transform. Bus. Econ. 2008, 7, 163-165.

28. Peldschus, F. Experience of the game theory application in construction management. Technol. Econ. Dev. Econ. 2008, 14, 531-545. [CrossRef]

29. Podvezko, V. Book review: Game theory in building technology and management. Bus. Econ. Manag. 2008, 9, 237-239. [CrossRef] 
30. Homburg, C.; Scherpereel, P. How should the cost of joint risk capital be allocated for performance measurement? Eur. J. Oper. Res. 2008, 187, 208-227. [CrossRef]

31. Su, B.B.; Chang, H.; Chen, Y.-Z.; He, D.R. A game theory model of urban public traffic networks. Phys. Stat. Mech. Appl. 2007, 379, 291-297. [CrossRef]

32. Sun, L.-J.; Gao, Z.-Y. An equilibrium model for urban transit assignment based on game theory. Eur. J. Oper. Res. 2007, 1, 305-314. [CrossRef]

33. Meszek, W. The analysis of property value increase as a result of infrastructural investment projects. Int. J. Environ. Pollut. 2008, 35, 345. [CrossRef]

34. Grzyl, B.; Miszewska-Urbańska, E.; Siemaszko, A. Safety of investment process parties in the aspect of construction work contract. Zesz. Nauk. Wyższa Szk. Oficer. Wojsk Lądowych Im Gen T Kościuszki 2017, Nr 4. [CrossRef]

35. Grzyl, B.; Apollo, M. Umowa o roboty budowlane w aspekcie podziału ryzyka stron. Inżynieria Morska $i$ Geotechnika 2015, 838-843. [CrossRef]

36. Kembłowski, M.W.; Grzyl, B.; Siemaszko, A. Game Theory Analysis of Bidding for a Construction Contract. IOP Conf. Ser. Mater. Sci. Eng. 2017, 245. [CrossRef]

37. Anysz, H.; Ibadov, N. Neuro-fuzzy predictions of construction site completion dates. Tech. Trans. 2017, 6. [CrossRef]

38. Juszczyk, M.; Kozik, R.; Leśniak, A.; Plebankiewicz, E.; Zima, K. Errors in the Preparation of Design Documentation in Public Procurement in Poland. Procedia Eng. 2014, 85, 283-292. [CrossRef]

39. Leśniak, A.; Plebankiewicz, E. Modeling the Decision-Making Process Concerning Participation in Construction Bidding. J. Manag. Eng. 2015, 31, 4014032. [CrossRef]

40. Antoniou, F.; Aretoulis, G.N.; Konstantinidis, D.; Kalfakakou, G.P. Engineers' Perception of Contract Types' Performance for Highway Construction Projects. Int. J. Appl. Behav. Econ. IJABE 2013, 2, 1-24. [CrossRef]

41. Ianole, R. Applied Behavioral Economics Research and Trends; IGI Global: Hershey, PA, USA, 2001; ISBN 978-1-5225-1826-6.

42. Shi, Q.; Zhu, J.; Li, Q. Cooperative Evolutionary Game and Applications in Construction Supplier Tendency. Available online: https:/ /www.hindawi.com/journals/complexity/2018/8401813/ (accessed on 8 March 2019).

43. Jide, S.; Xincheng, W.; Liangfa, S. Research on the mobility behavior of Chinese construction workers based on evolutionary game theory. Econ. Res.-Ekon. Istraživanja 2018, 31, 1-14. [CrossRef]

44. Kembłowski, M.W.; Grzyl, B.; Siemaszko, A. Game Theory Analysis of Bidding for a Construction Contract. In IOP Conference Series: Materials Science and Engineering; IOP Publishing: Bristol, England, 2017; Volume 245, p. 062047.

45. Hargreaves-Heap, S.; Varoufakis, Y. Game Theory: A Critical Introduction, 2nd ed.; Routledge: London, UK; New York, NY, USA, 2004; ISBN 978-0-415-25095-5.

(C) 2019 by the authors. Licensee MDPI, Basel, Switzerland. This article is an open access article distributed under the terms and conditions of the Creative Commons Attribution (CC BY) license (http://creativecommons.org/licenses/by/4.0/). 